B L $\mathrm{O}$ O M S S B U R Y

EDUCATION AND

CHILDHOOD STUDIES

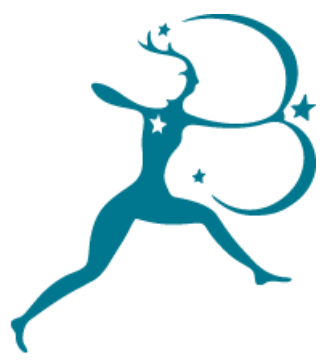

Forbes, Dianne. "Digital Technologies and Online Learning in Primary Education (New Zealand)." Bloomsbury Education and Childhood Studies. London: Bloomsbury Academic, 2019.

Bloomsbury Education and Childhood Studies. Web. 27 Jun. 2019.

<http://dx.doi.org/10.5040/9781350995932.0027>.

Accessed from: www.becs-bloomsbury.com

Accessed on: $\quad$ Fri Jun 282019 14:39:23 New Zealand Standard Time

Access provided by: BECS Contributor

Copyright $(\odot$ Bloomsbury Publishing PIc 50 Bedford Square London WC1B 3DP UK 1385

Broadway New York NY 10018 USA 2019 


\section{Digital Technologies and Online Learning in Primary Education (New Zealand)}

by Dianne Forbes,

DOI:10.5040/9781350995932.0027

Publisher:

Bloomsbury Publishing Plc

Identifier:

b-9781350995932-027

\section{FULL ARTICLE}

\section{Research on digital technologies and online learning}

Two key sources of research on digital technologies and online learning come in the form of largescale surveys of schools. First, Research New Zealand's survey (Johnson, Maguire, and Wood 2017) of more than 300 primary schools reports that schools use a mix of desktop devices, laptops, Chromebooks, and tablets. Findings indicate that most New Zealand schools have a strategic plan for the use of digital technologies in learning, incorporating consideration of safety, teacher professional development, and infrastructure. Increasingly, schools seek input from students on the use of digital technologies for learning. Most schools make use of Cloud platform resources for teaching and learning, with Google Classroom being the most popular. A majority of students access online learning resources, including online educational games.

Parallel to the work of Research New Zealand, Bolstad (2017), working for the New Zealand Council of Educational Research, surveyed parents and school leaders nationally, about the role and impact of digital technologies for learning. Teachers report that the use of digital technologies is often limited to practising skills, searching, and presenting documents and slideshows. Parents indicated that they valued opportunities for learning through digital technologies at school, alongside a balance of other learning activities and opportunities.

While the large surveys paint a broad picture of the use of digital technologies in New Zealand primary schools, there is a proliferation of small-scale research studies. A popular focus for these in recent years is mobile learning, particularly the use of iPads in primary school classrooms, learning with apps and mixed realities (virtual/augmented reality) (e.g., Calder and Murphy 2017; Cowie and Williams 2013).

\section{History}

Long before the iPad, an early use of instructional technology in New Zealand primary schools was radio in the late 1920s, followed by filmstrips in the 1930s. Government subsidies were provided to schools to purchase filmstrip projectors. A National Film Library was established in 1942. In 1948, all New Zealand schools were closed due to a polio epidemic, and children learned via radio broadcast lessons from the Correspondence School. Later, television was used to some extent in New Zealand schools, along with video recorders. Computers started to appear in primary schools in the 1990s. Initially, all of a school's computers may have been grouped together in one room, a computer laboratory or suite, available for classes to visit on a weekly basis. Gradually, computers were distributed around classrooms, with the intention that students would make more frequent and 
integrated use of the devices across the curriculum. Often, this involved a roster where each child had a "turn" on the computer, and/or where students typed up their written work (publishing a story) and played games for mathematics. Popular programs in the 1990s came on CD-ROM and included the likes of "Where in the world is Carmen San Diego?"

By the turn of the century, the first digital classrooms started to appear, with a higher ratio of computers to students and internet access. Schools/classrooms that were not technology-enriched to this extent would make use of a mobile stock of laptops known as "Computers on Wheels" or COWs. Digital video cameras were also popular in classrooms at this time, leading to studentgenerated movies. Subsequently, the iPad made its appearance, followed by cheaper tablet devices. iPod Touch had a short period of use in classrooms. At the time of writing, the Chromebook is one of the most popular devices due to cost and simplicity.

\section{Infrastructure}

Network for Learning (N4L) is a managed network providing schools with government-funded access to reliable, fast, safe internet connections with uncapped data. Safety features include filtering and firewall security, as well as a threat protection service that targets malware and phishing scams. N4L is available in 98 percent of New Zealand schools. A current initiative involves piloting the expansion of the N4L managed network to the homes of students who do not have internet access.

\section{Challenges}

There is a wide variation in the use of digital technologies and online learning, across schools and between individual classrooms. Some schools place greater priority on digital learning than others, while individual teachers may lack confidence and expertise to make effective use of technologies for learning. This can mean the use of technology is limited to word processing on a computer, or playing a drill and practice game on an iPad, often as a reward for completion of other work. A lack of technical support can be a challenge for some schools.

Equitable access is a challenge, and across the country, charitable trusts help families to buy Chromebooks for their children, spreading weekly payments over several years. Digital hubs for communities also enable schools to share internet access with their wider community. Building upon this is a new Ministry of Education initiative to promote Equitable Digital Access for Students (EDA4S). In particular, EDA4S targets students who do not have internet access at home (approximately 100,000 students in 40,000 households), with the aim of providing internet to continue learning online at home.

\section{Opportunities for rural and remote students}

\section{Education by correspondence is provided via Te Aho o Te Kura Pounamu (formerly the} Correspondence School), delivered partially online, with audio-visual resources and online activities as well as offline activities. A state-funded service, Te Kura is in effect New Zealand's largest state school, providing a program based on the New Zealand Curriculum (Ministry of Education 2007), with personalized learning support. 
Further opportunities for rural students are available via the VLN Primary School, supported by the Ministry of Education, but funded by a collaborative community of participating schools. The aim of the VLN Primary is to provide opportunities for students at schools around the country to access online learning that might otherwise not be available to them. Originally established to make tuition in a range of languages other than English available to schools around the country, the VLN Primary now provides cross-curricular opportunities, enabling children to study subjects that may not be taught at their school, particularly if it is a small rural school.

\section{Technology and other innovations}

It is now commonplace for New Zealand primary schools to encourage or mandate that students bring their own device to school for learning. Known as BYOD, the strategy releases schools from the expense and responsibility of providing digital devices, while ensuring that all children have access to their own device for use at school and home. Chromebooks are ideal for this purpose at primary school, due to the relatively low cost and simple user interface.

Increasingly, the architecture of primary schools in New Zealand is changing, with the emergence of the modern/innovative/flexible learning environment (MLE/ILE/FLE). An ILE is an open-plan space, larger than a regular classroom, built to accommodate large groups of students with several teachers (e.g., seventy students; two to three teachers). Intended as a technology-enriched, collaborative and student-centered learning environment, the shift toward ILEs is a further innovation that is influencing how primary students learn and how technology is utilized in the primary school.

While cross-curricular learning through digital technologies has long been an emphasis in New Zealand, the addition of digital technologies as a curriculum content area in its own right is a new initiative. Rather than an emphasis on digital technologies as pedagogical tools, the new content focuses on how the digital technologies work and on how that technical working knowledge can be applied to solve problems. Within the technology curriculum, the two new areas are: computational thinking (core programming concepts) and designing and developing digital outcomes (digital solutions). By 2020, this new digital technology content is to be implemented in all New Zealand schools, from primary level.

\section{Further reading and online resources}

Cardno, C., E. Tolmie, and J. Howse. 2017. "“New Spaces - New Pedagogies: Implementing Personalised Learning in Primary School Innovative Learning Environments" ." Journal of Educational Leadership, Policy and Practice 32 (1): 111-124. Accessed December 7, 2018. https://search-informit-comau.ezproxy.waikato.ac.nz/documentSummary; dn=021942398177622;res=IELHSS .

Earl, K. and D. L. Forbes. 2015. "Connected Learners: Transforming Learning through ICT." In The Professional Practice of Teaching in New Zealand, 5th edition, edited by D. Fraser and M. Hill, 216239. Melbourne : Cengage Learning .

McLean, K. J. 2016. "“The Implementation of Bring Your Own Device (BYOD) in Primary [elementary] Schools" ." Frontiers in Psychology 7 (1739). doi: 10.3389/fpsyg.2016.01739.

Ministry of Education. n.d. "Enabling e-Learning." Accessed December 7, 2018. http://elearning.tki.org.nz . 
Te Kura, the Correspondence School. 2018. "Learn Your Way." Accessed December 7, 2018. http://www.tekura.school.nz/ .

\section{References}

Bolstad, R. 2017. "Digital Technologies for Learning: Findings from the NZCER National Survey of Primary and Intermediate Schools 2016." Accessed December 7, 2018. http://www.nzcer.org.nz/research/publications/digital-technologies-learning-national-survey .

Calder, N. and C. Murphy. 2017. " Introduction to Special Issue: Mobile Technologies and Learning" ." Teachers and Curriculum 17 (2): 3-5 .

Cowie, B. and J. Williams. 2013. " "Special Issue: Knowledge Building in New Zealand Schools: The Journey Begins" ." Computers in New Zealand Schools: Learning, Teaching, Technology 25 (1): 1-2 . Johnson, M., J. Maguire, and A. Wood. 2017. Digital Technologies in Schools 2016-17. Accessed December 7, 2018. https://2020.org.nz/wp-content/uploads/2014/05/Digital-Technologies-inSchools-2016-17-04-05-2017-FINAL.pdf .

Ministry of Education. 2007. The New Zealand Curriculum . Wellington : Learning Media.

\section{Glossary}

\section{Bring your own device (BYOD)}

Students are encouraged to bring a personally owned device (e.g., iPad, Chromebook, or laptop) to school for learning purposes.

\section{Computers on Wheels (COWs)}

A set of devices mobilized for transporting around classrooms to enable multiple classes to use the technologies at different times.

\section{Equitable Digital Access for Students (EDA4S)}

The extension of the managed network (N4L) to surrounding communities.

\section{Modern/innovative/flexible learning environment (MLE/ILE/FLE)}

Various descriptors of open plan, technology-rich classrooms, where larger groups of students work with multiple teachers in a collaborative space.

Network for Learning (N4L)

A Crown Company that connects 98 percent of New Zealand schools to internet services, through our safe and secure Managed Network. www.n4l.co.nz/ .

Te Aho o Te Kura Pounamu (Te Kura; formerly the Correspondence School)

The state-funded distance education provider in New Zealand.

Virtual Learning Network (VLN)

A charitable trust that works collaboratively with schools to engage students in online learning. 